\title{
Stabilization of pitch-based carbon fibers accompanying electron beam irradiation and their mechanical properties
}

\author{
Mi-Seon Park, Yoonyoung Ko, Min-Jung Jung and Young-Seak Lee \\ Department of Applied Chemistry and Biological Engineering, Chungnam National University, Daejeon 305-764, Korea
}

\section{Article Info}

Received 23 February 2015

Accepted 27 March 2015

*Corresponding Author

E-mail: youngslee@cnu.ac.kr Tel: $+82-42-821-7007$

\section{Open Access}

DOI: http://dx.doi.org/

10.5714/CL.2015.16.2.121

This is an Open Access article distributed under the terms of the Creative Commons Attribution Non-Commercial License (http://creativecommons.org/licenses/ by-nc/3.0/) which permits unrestricted non-commercial use, distribution, and reproduction in any medium, provided the original work is properly cited.

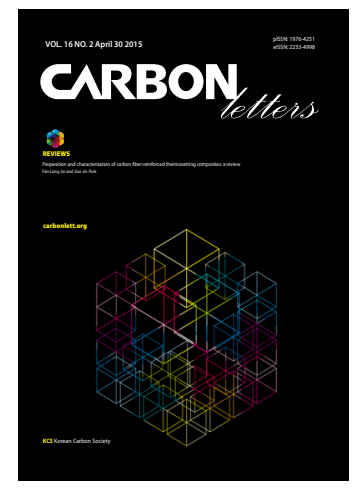

http://carbonlett.org

pISSN: $1976-4251$

elSSN: 2233-4998

Copyright $\odot$ Korean Carbon Society

\begin{abstract}
Carbon fibers are prepared by stabilizing pitch fibers accompanying electron beam (E-beam) irradiation. The carbon fibers pretreated by E-beam irradiation achieve a higher stabilization index than the carbon fibers that are only heat-stabilized. In addition, the carbon fibers subjected to E-beam irradiation in the stabilization step exhibit a comparable tensile strength to that of general purpose carbon fibers. The carbon fibers pretreated with an absorbed dose of $3000 \mathrm{kGy}$ have a tensile strength of $0.54 \mathrm{GPa}$ for a similar fiber diameter. Elemental, Fourier-transform infrared spectroscopy, and thermogravimetric analyses indicate that Ebeam irradiation is an efficient oxidation and dehydrogenation treatment for pitch fibers by showing that the intensity of the aliphatic $\mathrm{C}-\mathrm{H}$ stretching and aromatic $\mathrm{CH}_{2}$ bending (out-ofplane) bands significantly decrease and carbonyl and carboxylic groups form.
\end{abstract}

Key words: carbon fibers, pitch, stabilization, mechanical properties

\section{Introduction}

Carbon fibers ( $\mathrm{CFs}$ ) have recently attracted extensive attention as promising materials for a variety of applications, such as in automobiles, the aerospace industry, and construction, as well as in general engineering product markets [1,2]. Interest in CFs has been gradually growing due to their high strength, high stiffness, dimensional stability, and low coefficient of thermal expansion [3]. CFs having high and general performance are primarily produced from polyacrylonitrile (PAN) and pitches. To date, PAN-based CFs mostly have been applied in composites for aircrafts and automobiles. However, pitch-based CFs have been recently researched as an alternative because of their lower raw material costs and higher productivity compared to PAN-based CFs [4,5].

The stabilization process is an important step in the production of high performance CFs [6] because the stabilization determines the mechanical properties of the CFs, such as the Young's modulus and tensile strength, after a high temperature heat-treatment process referred to as carbonization [7]. Stabilization provides the surface and interior of the fibers with oxygen functional groups to prevent melting of the fibers by maintaining a fibrous structure during carbonization. Stabilization is thus a crucial part of the CF preparation process when producing high and general performance CFs.

Electron beam (E-beam) irradiation has been extensively applied in polymer modification and is used to rapidly generate free radicals [8]. Shin et al. [9] recently reported the use of E-beam irradiation to stabilize PAN fibers in the preparation of PAN-based CFs. In addition, the molecular weight of the polymer increased greatly when free radical termination was minimized [10]. The stabilization of pitch-based CFs accompanying E-beam irradiation, however, has not been reported to date.

The present study introduced E-beam irradiation as a stabilization step in CF production to obtain general purpose CFs at a lower stabilization temperature and then investigated the effects of E-beam irradiation on the stabilization and mechanical properties of the final CF 
material. The CFs heat-stabilized at higher temperatures were not affected by the E-beam pretreatment. However, the CFs heat-stabilized at lower temperatures revealed that E-beam pretreatment significantly improved the tensile strength after carbonization as well as the stabilization index (SI) of CFs.

\section{Experimental}

\subsection{Preparation of pitch fibers}

The pitch fibers used in this study were prepared from a reformed pitch precursor using a novel melt-spinning procedure. The pyrolyzed fuel oil (PFO) used in the reforming pitch was supplied by the GS Caltex Refinery Company in Korea and the obtained isotropic pitch had a softening point of $250^{\circ} \mathrm{C}$. The pitch reforming procedure, which consisted of a subsequent distillation and thermal treatment, has been previously described $[11,12]$. In the melt-spinning method, a metal-syringe apparatus with a $10 \mathrm{~g}$ sample capacity was used to extrude the melted pitch through a mono-hole spinneret with a diameter of $0.1 \mathrm{~mm}$. The following melt-spinning conditions were maintained throughout the process: a tip-to-collector distance of $20 \mathrm{~cm}$ and a collector speed of $1600 \mathrm{rpm}$. The spinning temperature and extrusion pressure of the pitch for melt-spinning were $300^{\circ} \mathrm{C}$ and 2 bar, respectively. The diameter of the obtained pitch fibers was approximately $17-20 \mu \mathrm{m}$

\subsection{Stabilization and carbonization procedure}

The as-spun fibers were stabilized using E-beam irradiation and heat to investigate the effect of the E-beam irradiation on the fiber stabilization. First, the as-spun pitch fibers were subjected to Ebeam irradiation at an electron accelerating voltage of $1.14 \mathrm{MeV}$ and current of $15.2 \mathrm{~mA}$. The absorbed doses of the E-beam were 1000, 2000, and $3000 \mathrm{kGy}$. During the E-beam irradiation, the irradiation was paused at $500 \mathrm{kGy}$ increments of absorbed dose to prevent the fibers from melting and sticking. Heat-stabilization was subsequently conducted under an air atmosphere in a forced convection oven. The air (zero air, 20.8\% $\mathrm{O}_{2}+\mathrm{N}_{2}$ balance, Special Gas, Korea) flow rate was $500 \mathrm{cc} / \mathrm{min}$. The pitch fibers were heattreated at a heating rate of $1^{\circ} \mathrm{C} / \mathrm{min}$ and then held at $250^{\circ} \mathrm{C}$ for 2 h. A sample of pitch fibers only subjected to heat stabilization was also prepared at $250^{\circ} \mathrm{C}$ for $2 \mathrm{~h}$ as a comparison group. After the stabilization, the fibers were carbonized at $1000^{\circ} \mathrm{C}$ for $1 \mathrm{~h}$ under a nitrogen atmosphere at a heating rate of $5^{\circ} \mathrm{C} / \mathrm{min}$ in an electric furnace. The carbonized fibers were allowed to naturally cool to room temperature. The prepared samples were labeled according to the stabilization conditions as $250 \mathrm{H}, 1000 \mathrm{E} 250 \mathrm{H}, 2000 \mathrm{E} 250 \mathrm{H}$, and $3000 \mathrm{E} 250 \mathrm{H}$, where $\mathrm{H}$ and $\mathrm{E}$ refer to heat-treatment and $\mathrm{E}$ beam irradiation, respectively.

\subsection{Characterizations}

Elemental analyses of the pitch fibers and stabilized fibers were performed by using an elemental analyzer (EA 1112, Thermo Fisher Scientific, USA) to confirm the $\mathrm{C}, \mathrm{H}, \mathrm{O}$, and $\mathrm{N}$ contents of the treated and untreated pitch fibers. The samples were burned at $1800^{\circ} \mathrm{C}$ and the atomic content was detected by a ther- mal conductivity detector. Fourier-transform infrared spectroscopy (FT-IR) spectra were recorded to investigate the chemical structure before and after stabilization using an FT-IR spectrometer (FTS-175C; Bio-Rad Laboratories, Cambridge Inc., USA) in the range of approximately $3,800-450 \mathrm{~cm}^{-1}$ using a beam splitter of $\mathrm{Ge}$ on $\mathrm{KBr}$. A thermogravimetric analysis (TGA) was conducted using a thermal analyzer (TGA/DSC 1; Mettler-Toledo Inc., Korea) to investigate the stabilization behavior during the stabilization process. The temperature was increased from $25^{\circ} \mathrm{C}$ to $1000^{\circ} \mathrm{C}$ at a heating rate of $10^{\circ} \mathrm{C} / \mathrm{min}$. An X-ray diffraction (XRD) analysis was also performed to calculate the stabilization level of the treated fibers using an X-ray diffractometer (D8 DISCOVER; Bruker AXS, Germany) with $\mathrm{Cu} \mathrm{K} \alpha$ radiation generated by a $3 \mathrm{~kW} X$-ray tube with a $\mathrm{Cu}$ target over the $2 \theta$ range of $10^{\circ}-80^{\circ}$. The morphologies of the samples were investigated using a field emission scanning electron microscope (FE-SEM; Hitachi, S-5500, Korea Basic Science Institute, Jeonju Center).

\subsection{Mechanical properties of the CFs}

The tensile strengths of single fibers after carbonization were measured using a single fiber tester (FAVIMAT+, Textechno, Germany) equipped with a load cell of $210 \mathrm{cN}$. The CFs for tensile testing were fastened to a clamp with a length of $25 \mathrm{~mm}$ and a tensile load was then applied at a speed of $5 \mathrm{~mm} / \mathrm{min}$. The tensile experiments were repeated for at least 15 pieces per stabilization condition, and the tensile strength values were calculated from the results for the fibers that remained undamaged after the test using the following equation:

$$
\mathrm{T}=\mathrm{P} / \mathrm{A}
$$

where $\mathrm{T}$ is the tensile strength $(\mathrm{Pa})$ of the fibers, $\mathrm{P}$ is the load $(\mathrm{N})$ at which fibers broke, and $\mathrm{A}$ is the cross-sectional area $\left(\mathrm{m}^{2}\right)$ of the tested fibers [13].

\section{Results and Discussion}

\subsection{Changes in chemical structures}

The stabilization of CFs is conducted to retain the fiber morphology after carbonization by removing the molten component of the CFs. Although the stabilization of PAN-based CFs entails cyclization of the nitrile groups $(-\mathrm{C} \equiv \mathrm{N})$ into conjugated carbonnitrogen double bonds $(-\mathrm{C}=\mathrm{N}-)$ and dehydrogenation of them into carbon-carbon double bonds [14], the process for pitch-based CFs endows the samples with heat resistance after dehydrogenation of the carbon six-membered ring structure. The chemical and mechanical properties of the CFs depend on the stabilization level.

Elemental analyses were carried out to investigate the elemental components before and after stabilization. Table 1 shows the $\mathrm{C}, \mathrm{H}, \mathrm{O}$, and $\mathrm{N}$ contents introduced on fibers that were treated with different stabilization conditions. The introduced oxygen content was $2.33,10.17,10.28$, and 11.28 at $\%$ for $250 \mathrm{H}$, $1000 \mathrm{E} 250 \mathrm{H}, 2000 \mathrm{E} 250 \mathrm{H}$, and $3000 \mathrm{E} 250 \mathrm{H}$, respectively. The oxygen content in the fibers increased as a function of the absorbed dose during stabilization involving E-beam irradiation. However, the content of both carbon and hydrogen decreased. 
Table 1. Elemental analysis results of pitch fibers and pitch fibers stabilized under heat treatment after various E-beam conditions

\begin{tabular}{cccccc}
$\begin{array}{c}\text { Elemental } \\
\text { analysis } \\
\text { (at\%) }\end{array}$ & $\begin{array}{c}\text { pitch } \\
\text { fibers }\end{array}$ & $250 \mathrm{H}$ & $1000 \mathrm{E} 250 \mathrm{H}$ & $2000 \mathrm{E} 250 \mathrm{H}$ & $3000 \mathrm{E} 250 \mathrm{H}$ \\
\hline $\mathrm{C}$ & 93.68 & 91.83 & 85.61 & 85.49 & 84.46 \\
$\mathrm{H}$ & 3.07 & 5.27 & 4.12 & 4.07 & 3.92 \\
$\mathrm{O}$ & 1.13 & 2.33 & 10.17 & 10.28 & 11.28 \\
$\mathrm{~N}$ & 2.12 & 0.57 & 0.10 & 0.16 & 0.34 \\
\hline
\end{tabular}

E-beam: electron beam.

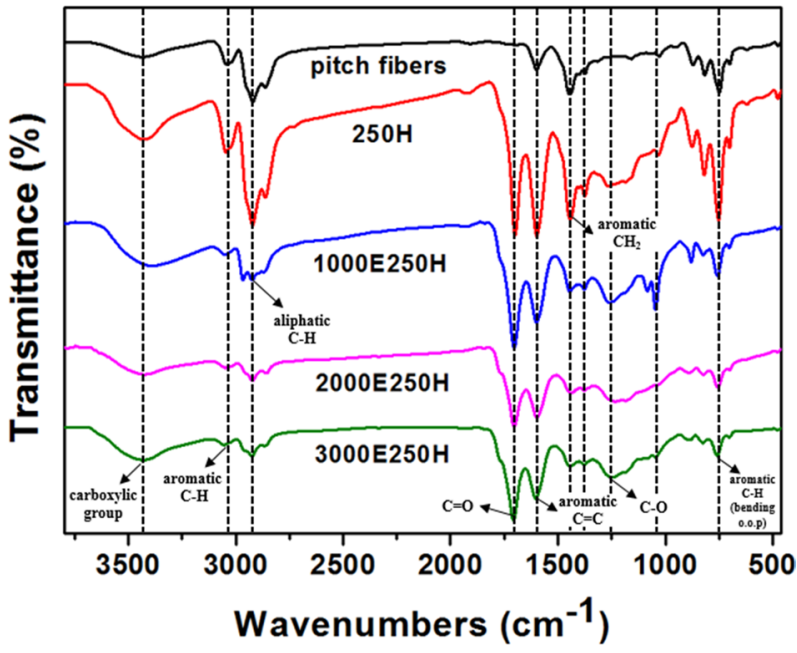

Fig. 1. Fourier-transform infrared spectra of the pitch fibers stabilized under the heat and electron beam conditions.

These results show that oxygen penetrated the fibers, liberating carbon and hydrogen atoms from the fibers during the stabilization, thus indicated that the existing molecules were converted into aromatic compounds via poly-condensation [15].

A FT-IR analysis was also conducted to investigate changes in the functional groups of the stabilized fibers, and the results are shown in Fig. 1. After only heat-stabilization at $250^{\circ} \mathrm{C}$, the band intensity at $3045,1598,1443$, and $751 \mathrm{~cm}^{-1}$ increased dramati- cally, corresponding to the $\mathrm{C}-\mathrm{H}$ stretching of aromatics, $\mathrm{C}=\mathrm{C}$ stretching of aromatics, $\mathrm{CH}_{2}$ bending of aromatics, and $\mathrm{C}-\mathrm{H}$ bending of aromatics (out-of-plane), respectively [16]. A band at $1699 \mathrm{~cm}^{-1}$ was assigned to $\mathrm{C}=\mathrm{O}$ stretching [17]. This band was observed at $1715 \mathrm{~cm}^{-1}$ for saturated aliphatic ketone and may be shifted to a lower absorption frequency due to delocalized electrons resulting from the presence of $\mathrm{C}=\mathrm{O}$ in the aromatic group. Another broad band at $3430 \mathrm{~cm}^{-1}$ indicated the hydroxyl stretching of $-\mathrm{COOH}$. These results show that, during the heat stabilization of the pitch fibers, carbonyl and carboxylic groups were introduced and simultaneously form conjugated carbon rings. In the case of the heat-stabilized sample, the $\mathrm{CH}$ stretching band of aliphatic at $2922 \mathrm{~cm}^{-1}$ became strong. This increase in intensity was likely due to the decomposition of some of the pitch fibers, particularly the low-molecular-weight fibers, by heat [18]. The increase in the hydrogen content of the heat-stabilized samples was attributed to the same phenomenon. In contrast, the E-beam pretreated pitch fibers showed significant decreases in the intensity of the $\mathrm{CH}$ stretching bands and the formation of an additional oxygen functional group ( $\mathrm{C}-\mathrm{O}$ stretching band) at approximately $1262 \mathrm{~cm}^{-1}$. In addition, the band for out-of-plane aromatic $\mathrm{C}-\mathrm{H}$ bending at $751 \mathrm{~cm}^{-1}$ decreased dramatically, indicating that hydrogen was removed via poly-condensation. It is thus believed that the E-beam irradiation helps the oxidation of pitch fibers and will further improve the mechanical properties of the CFs.

\subsection{Evaluation of stabilization}

\subsubsection{Thermal characteristics}

A TGA was conducted to evaluate the thermal characteristics depending on the stabilization conditions. Fig. 2 contains the TG curves for the pitch fibers and the derived heat-treated only and E-beam accompanied stabilized fibers. Fig. 2a shows that the weight changed under a nitrogen atmosphere up to $1000^{\circ} \mathrm{C}$ at a heating rate of $10^{\circ} \mathrm{C} / \mathrm{min}$.

The thermal behavior of the pitch fibers dramatically changed after $450^{\circ} \mathrm{C}$, showing a weight change of $25 \%$ at $500^{\circ} \mathrm{C}$, which indicated the occurrence of dehydrogenation above $250^{\circ} \mathrm{C}[6]$. The thermal behaviors of the stabilized samples were similar to those of the pitch fibers up to approximately $400^{\circ} \mathrm{C}$. However, above $400^{\circ} \mathrm{C}$, the behaviors became different, suggesting differences in the thermal stability. The weight of the stabilized fibers
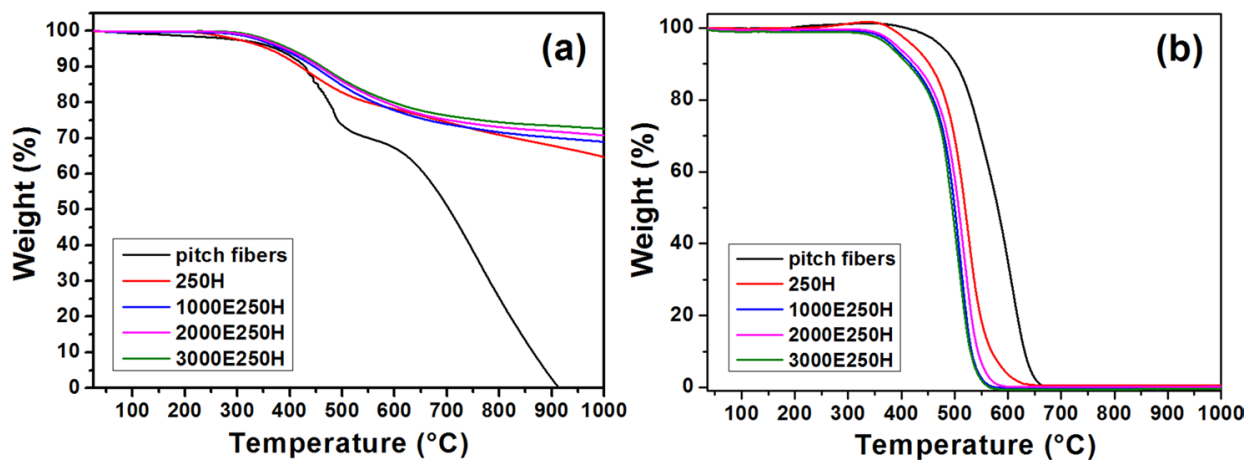

Fig. 2. Thermogravimetric analysis curves of pitch fibers stabilized under heat and electron beam conditions in (a) nitrogen and (b) air atmosphere, respectively. 


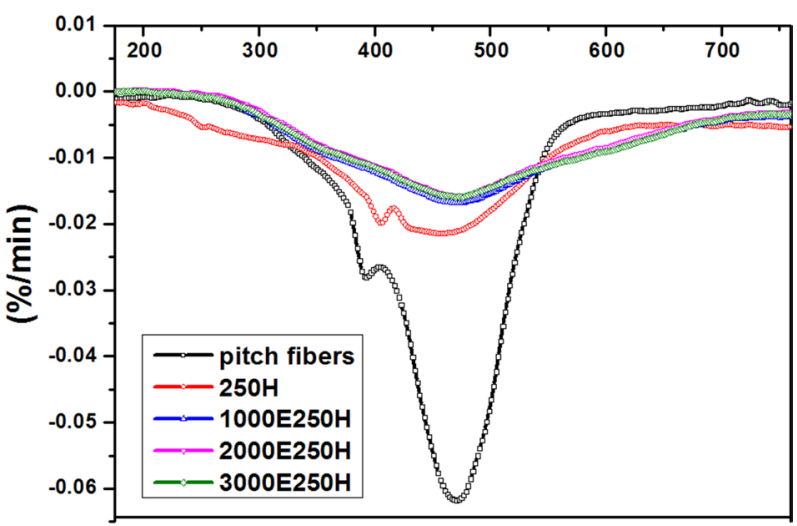

Temperature $\left({ }^{\circ} \mathrm{C}\right)$

Fig. 3. Derivative thermogravimetric analysis curves of pitch fibers stabilized under heat and electron beam conditions.

decreased gradually, and the weight change at $500^{\circ} \mathrm{C}$ was only $15 \%$. The increase in weight loss of the pitch fibers was attributed to the inclusion of a low molecular compound [18]. In addition, the weight of the pitch fibers was $0 \%$ at slightly above $900^{\circ} \mathrm{C}$, which indicated that the pitch had thermally decomposed. The reduced weight changes exhibited by the E-beam-pretreated fibers was attributed to the removal of the remaining oxygen functional groups, such as $-\mathrm{OH}$ and $-\mathrm{COOH}$, which formed radicals and then condensed by linking $[9,19]$, as previously shown in Fig. 1. Furthermore, the E-beam-pretreated fibers had a higher carbonization yield at $1000^{\circ} \mathrm{C}$ than the fibers only subjected to heat-stabilization. In particular, the carbonization yield of the $3000 \mathrm{E} 250 \mathrm{H}$ fibers was $73 \%$. Fig. $2 \mathrm{~b}$ shows the TGA curves obtained in an air atmosphere, revealing that the stabilized fibers having more oxygen content experienced a weight decrease earlier than the untreated and heat-stabilized only fibers, as the oxygen functionalities decomposed above $250^{\circ} \mathrm{C}$, followed by weakening of the bonding structure of the fibers. The derivative of the TGA (dTGA) curves, presented in Fig. 3, shows the degree of weight change based on the peak intensity at a specific temperature. The main peak of the fibers increased with the E-beam treatment severity. The main peak was located at approximately $471^{\circ} \mathrm{C}$ for the pitch fibers and the fibers treated at $250^{\circ} \mathrm{C}$ and approximately $475^{\circ} \mathrm{C}$ for the E-beam-pretreated fibers. In addition, the peak intensity of the heat-treated only fibers was lower for the same temperature. After stabilization accompanying E-beam irradiation, the peak intensity was markedly lower than that of the pitch fibers, with a slight shift toward higher temperatures. This finding indicated that E-beam irradiation facilitated oxygen permeation into the surface and interior of the pitch fibers during oxidation, as the decrease in weight occurred at higher temperature, indicating that melting was prevented [20,21]. These results suggest that E-beam irradiation promotes the condensation polymerization and infusibility of the pitch fibers, which progressed in thermosetting polymers. This improvement is believed to affect the mechanical properties of the fibers after carbonization.

\subsubsection{Stabilization level}

The stabilization of pitch fibers is a process where the fiber structure progresses gradually into another structure [22]. The

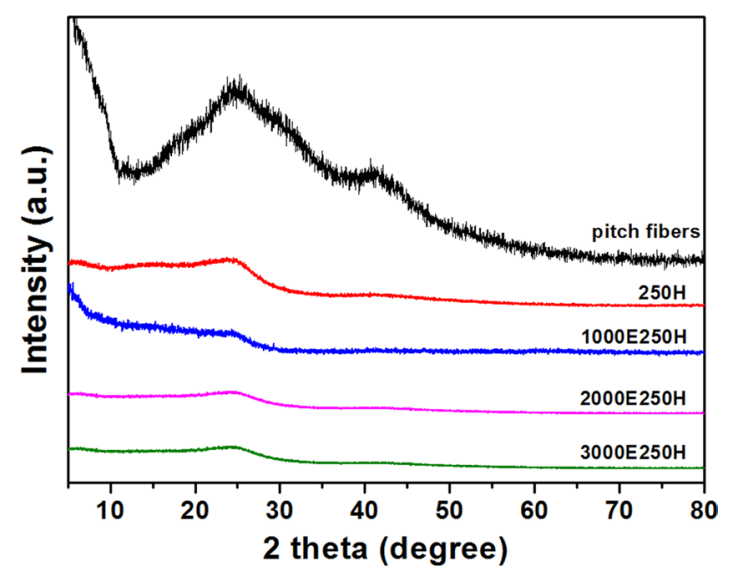

Fig. 4. X-ray diffraction patterns for pitch fibers and pitch fibers stabilized under heat and electron beam conditions.

Table 2. X-ray diffraction parameter data corresponding to the pitch fibers and the pitch fibers stabilized under heat treatment with various E-beam conditions

\begin{tabular}{ccccc} 
Samples & $\begin{array}{c}\text { Peak intensity } \\
(\mathrm{CPS})\end{array}$ & $\begin{array}{c}\text { Peak center } \\
\left({ }^{\circ}\right)\end{array}$ & FWHM & SI (\%) \\
\hline Pitch fibers & 987 & 24.63 & 3.92 & \\
$250 \mathrm{H}$ & 279 & 24.36 & 4.02 & 71.69 \\
$1000 \mathrm{E} 250 \mathrm{H}$ & 176 & 23.70 & 2.34 & 82.09 \\
$2000 \mathrm{E} 250 \mathrm{H}$ & 155 & 23.60 & 2.75 & 84.23 \\
$3000 \mathrm{E} 250 \mathrm{H}$ & 96 & 24.25 & 2.26 & 90.23 \\
\hline
\end{tabular}

E-beam: electron beam, FWHM: full width at half maximum, SI: stabilization index.

structural change during the stabilization can be confirmed by a XRD analysis. From the series of XRD patterns shown in Fig. 4 , the change in the peak intensity at a specific $2 \theta$, which corresponds to a change in the structure of the stabilized fibers, can be expressed as the SI as follows [23]:

$$
\mathrm{SI}=\frac{I_{0}-I_{i}}{I_{0}} \times 100 \%
$$

where $I_{0}$ is the intensity corresponding to the $\left(\begin{array}{lll}0 & 0 & 2\end{array}\right)$ diffraction peak, which is near the $2 \theta$ value of approximately $26^{\circ}$ arising from the pitch fibers. $I_{\mathrm{i}}$ is the intensity of the peak from the stabilized fibers at approximately $2 \theta=26^{\circ}$. The peak at $26^{\circ}$ in XRD generally indicates a crystal structure or an orientation close to graphite. However, for stabilized pitch fibers that were not carbonized, this peak was shifted to around $24^{\circ}$ in this study. The SI values could be easily determined by the above equation and are listed in Table 2.

From the XRD study of stabilized fibers, the pitch fibers showed a peak at a specific $2 \theta$ (approximately $26^{\circ}$ ), which is different from PAN fibers (approximately $16^{\circ}$ ) [22,23], and the intensity of the peaks also varied depending on the stabilization conditions. This explains why the synthetic mechanism and structural change of the pitch fibers are slightly different from those of the PAN fiber after heat treatment. This 
indicates that the pitch fibers also undergo structural change during stabilization, even though the aromatic compounds of the pitch fiber grew differently from cyclization of the PAN fibers. Furthermore, the mechanical properties of the pitch fibers were consistent with the results of SI calculated from the XRD analysis. This effect is thus likely also manifested in the pitch fibers.

As shown in Fig. 4, the peak intensity at approximately $26^{\circ}$ decreased after stabilization using heat and E-beam irradiation. Although the fiber that was heat-stabilized only showed a large decrease in the peak intensity, the fibers treated with E-beam irradiation showed even greater decreases. In addition, a larger decrease in the peak intensity was observed with increasing adsorbed dose. This was attributed to the excellent stabilization of the pitch fibers.

Comparing the SI depending on the stabilization conditions in Table 2, the $250 \mathrm{H}$ fibers had an SI of $71.69 \%$. As shown in Fig. 4 , the SI increased with increasing adsorbed dose, and the SIs for the $1000 \mathrm{E} 250 \mathrm{H}, 2000 \mathrm{E} 250 \mathrm{H}$, and $3000 \mathrm{E} 250 \mathrm{H}$ fibers were $82.09 \%, 84.23 \%$, and $90.23 \%$, respectively. We also tested the stabilization using only $3000 \mathrm{kGy}$ under the same conditions, and the resulting SI was $47.87 \%$. The calculated SI results were in accordance with the TGA and dTGA results.

\subsection{Mechanical properties after carbonization}

The fibers irradiated at only $3000 \mathrm{kGy}$ melted after carbonization at $1000^{\circ} \mathrm{C}$ for $1 \mathrm{~h}$ in a furnace, indicating that the stabilization was not successful. E-beam irradiation alone could not achieve perfect stabilization. However, heat-treatment after E-beam irradiation increased the tensile strength and Young's modulus. The tensile strength was $0.22,0.35,0.51$, and 0.54 $\mathrm{GPa}$ for the 250H, 1000E250H, 2000E250H, and 3000E250H fibers, respectively (Fig. 5). The Young's moduli were 26.5, 45.9, 50.9 , and $70.2 \mathrm{GPa}$ for the $250 \mathrm{H}, 1000 \mathrm{E} 250 \mathrm{H}, 2000 \mathrm{E} 250 \mathrm{H}$, and $3000 \mathrm{E} 250 \mathrm{H}$ fibers, respectively. These tensile strengths above $500 \mathrm{MPa}$ are comparable to the values of general purpose CFs derived from isotropic pitches [24,25]. The CFs prepared using E-beam irradiation achieved tensile strength on par with that of general purpose $\mathrm{CFs}$ obtained from pitch. The mechanical properties of the samples increased with increasing absorbed E-beam radiation dose, indicating that an increase in absorbed dose

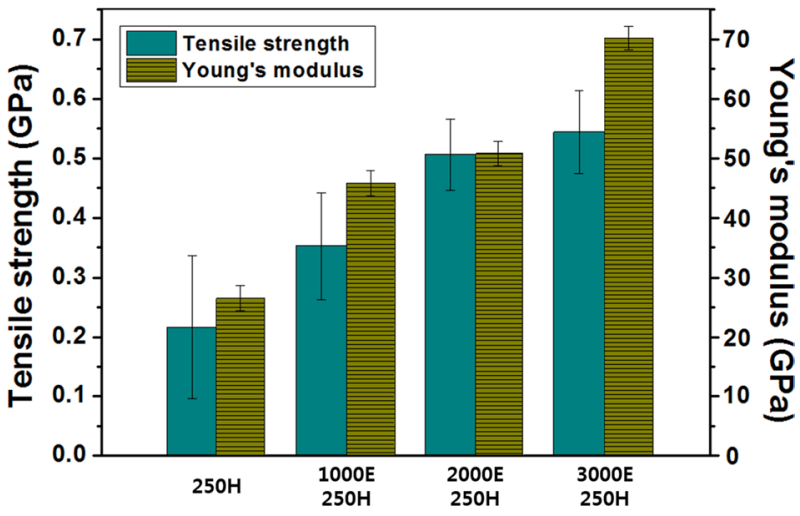

Fig. 5. Tensile strength and Young's modulus of carbon fibers prepared from pitch fibers stabilized by using heat and electron beam.

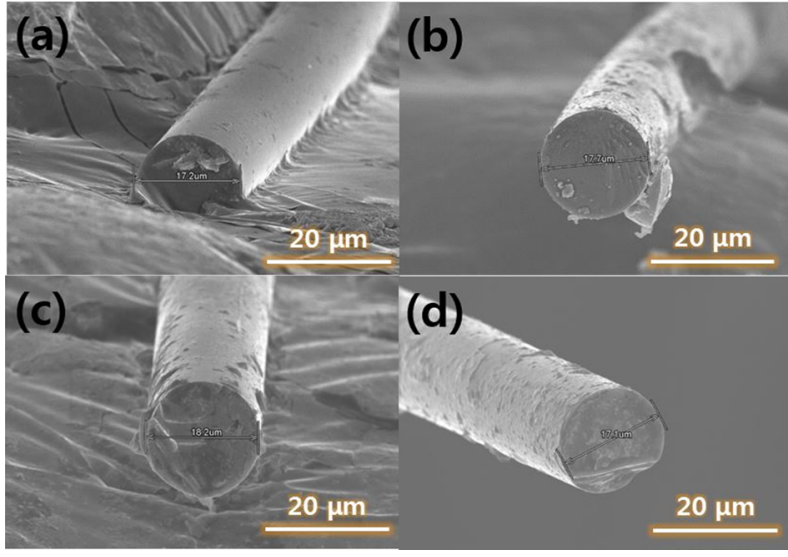

Fig. 6. Scanning electron microscope images of cross-section of (a) $250 \mathrm{H}$, (b) $1000 \mathrm{E} 250 \mathrm{H}$, (c) $2000 \mathrm{E} 250 \mathrm{H}$, and (d) $3000 \mathrm{E} 250 \mathrm{H}$, respectively, after carbonization at $1000^{\circ} \mathrm{C}$.

gradually improved the coherence of the carbonized fibers. The elongation thus decreased, significantly increasing the Young's modulus from 2000 to $3000 \mathrm{kGy}$. The $250 \mathrm{H}$ fibers were stabilized with an SI of $71.69 \%$ SI; however, the tensile strength was only $0.22 \mathrm{GPa}$. E-beam irradiation was thus an efficient way to stabilize the pitch fibers if followed by heat-treatment. In this study, oxidation and polymerization proceeded when the SI was above approximately $70 \%$ and did not proceed when the SI was lower than 50\%. Fig. 6a-d show cross-sectional images of the $\mathrm{CFs}$ after carbonization at $1000^{\circ} \mathrm{C}$. The cross-sectional images exhibited similar fiber diameters $(17-18 \mu \mathrm{m})$.

\section{Conclusions}

CFs were prepared through a stabilization process using Ebeam irradiation followed by heat-treatment. The EA and FTIR results showed that the fibers subjected to E-beam irradiation had high oxygen content, a weak $\mathrm{C}-\mathrm{H}$ stretching band, and the presence of $\mathrm{C}-\mathrm{O}$ groups as well as carbonyl and carboxylic groups compared to the fibers prepared without E-beam irradiation. The thermal resistance of the E-beam pretreated fibers increased, with TGA and dTGA results indicating smaller weight losses at the same temperature. These results were attributed to a higher SI obtained from E-beam treatment. The stabilization process accompanied by E-beam irradiation demonstrated that the use of the E-beam as a supplemental agent helped the pitch fibers transform into thermosetting polymers by oxidation and dehydrogenation. Furthermore, this process affected the mechanical properties of the $\mathrm{CFs}$, as the fibers treated with an absorbed dose of $3000 \mathrm{kGy}$ showed the highest tensile strength, $0.54 \mathrm{GPa}$, in this study.

\section{Acknowledgements}

This research was supported by the National Research Foundation of Korea (NRF) funded by the Ministry of Science, ICT \& Future Planning (No. 2013M2A2A6043697). 


\section{References}

[1] Kim JG, Im JS, Bae TS, Kim JH, Lee YS. The electrochemical behavior of an enzymatic biosensor electrode using an oxyfluorinated pitch-based carbon. J Ind Eng Chem, 19, 94 (2013). http://dx.doi. org/10.1016/j.jiec.2012.07.008.

[2] Kim BJ, Lee YS, Park SJ. Novel porous carbons synthesized from polymeric precursors for hydrogen storage. Int J Hydrogen Energy, 33, 2254 (2008). http://dx.doi.org/10.1016/j.ijhydene.2008.02.019.

[3] Yang Q, Liu J, Li S, Wang F, Wu T. Fabrication and mechanical properties of $\mathrm{Cu}$-coated woven carbon fibers reinforced aluminum alloy composite. Mater Des, 57, 442 (2014). http://dx.doi. org/10.1016/j.matdes.2013.12.064.

[4] Mochida I, Toshima H, Korai Y, Matsumoto T. Blending mesophase pitch to improve its properties as a precursor for carbonfibre. Part 1: Blending of PVC pitch into coal-tar and petroleumderived mesophase pitches. J Mater Sci, 23, 670 (1988). http:// dx.doi.org/10.1007/BF01174704.

[5] Kim BJ, Eom Y, Kato O, Miyawaki J, Kim BC, Mochida I, Yoon SH. Preparation of carbon fibers with excellent mechanical properties from isotropic pitches. Carbon, 77, 747 (2014). http://dx.doi. org/10.1016/j.carbon.2014.05.079.

[6] Arbab S, Zeinolebadi A. A procedure for precise determination of thermal stabilization reactions in carbon fiber precursors. Polym Degrad Stab, 98, 2537 (2013). http://dx.doi.org/10.1016/j.polymdegradstab.2013.09.014

[7] Jung DH, Lee YS, Rhee BS. The stabilization of mesophase pitch based carbon fiber. Hwahak Konghak, 29, 89 (1991).

[8] Vautard F, Ozcan S, Poland L, Nardin M, Meyer H. Influence of thermal history on the mechanical properties of carbon fiber-acrylate composites cured by electron beam and thermal processes. Composite A, 45, 162 (2013). http://dx.doi.org/10.1016/j.compositesa.2012.08.025

[9] Shin HK, Park M, Kang PH, Choi HS, Park SJ. Preparation and characterization of polyacrylonitrile-based carbon fibers produced by electron beam irradiation pretreatment. J Ind Eng Chem, 20, 3789 (2014). http://dx.doi.org/10.1016/j.jiec.2013.12.080.

[10] Schlemmer B, Bandari R, Rosenkranz L, Buchmeiser MR. Electron beam triggered, free radical polymerization-derived monolithic capillary columns for high-performance liquid chromatography. J Chromatogr A, 1216, 2664 (2009). http://dx.doi.org/10.1016/j. chroma.2008.09.003.

[11] Lee YS, Basova YV, Edie DD, Reid LK, Newcombe SR, Ryu SK. Preparation and characterization of trilobal activated carbon fibers. Carbon, 41, 2573 (2003). http://dx.doi.org/10.1016/S00086223(03)00376-2.

[12] Jung JY, Lee YS. Preparation of pitch from pyrolized fuel oil by electron beam radiation and its melt-electrospinning property, Carbon Lett, 15, 129 (2014). http://dx.doi.org/10.5714/
CL.2014.15.2.129.

[13] Wirawan R, Sapuan SM, Robiah Y, Khalina A. Elastic and viscoelastic properties of sugarcane bagasse-filled poly(vinyl chloride) composites. J Therm Anal Calorim, 103, 1047 (2011). http:// dx.doi.org/10.1007/s10973-010-1079-z.

[14] Xue Y, Liu J, Liang J. Correlative study of critical reactions in polyacrylonitrile based carbon fiber precursors during thermaloxidative stabilization. Polym Degrad Stab, 98, 219 (2013). http:// dx.doi.org/10.1016/j.polymdegradstab.2012.10.018.

[15] In SJ, Ryu SK, Rhee BS. Effect of stirring speed and $\mathrm{N}_{2}$-blowing rate on mesophase formation from naptha tar pitch. Hwahak Konghak, 27, 291 (1989).

[16] Awasthi K, Singh DP, Singh SK, Dash D, Srivastava ON. Attachment of biomolecules (protein and DNA) to amino-functionalized carbon nanotubes. New Carbon Mater, 24, 301 (2009). http:// dx.doi.org/10.1016/S1872-5805(08)60053-0.

[17] Zhang Y, Ma H, Zhang K, Zhang S, Wang J. An improved DNA biosensor built by layer-by-layer covalent attachment of multi-walled carbon nanotubes and gold nanoparticles. Electrochim Acta, 54, 2385 (2009). http://dx.doi.org/10.1016/j.electacta.2008.10.052.

[18] Vilaplana-Ortego E, Alcañiz-Monge J, Cazorla-Amorós D, Linares-Solano A. Stabilisation of low softening point petroleum pitch fibres by iodine treatment. Fuel Process Technol, 88, 265 (2007). http://dx.doi.org/10.1016/j.fuproc.2006.10.005.

[19] Jiang SZ. Focus on Combustion Research, Nova Science Publishers, New York, NY, 7 (2006)

[20] Jacquet N, Quiévy N, Vanderghem C, Janas S, Blecker C, Wathelet B, Devaux J, Paquot M. Influence of steam explosion on the thermal stability of cellulose fibres. Polym Degrad Stab, 96, 1582 (2011). http://dx.doi.org/10.1016/j.polymdegradstab.2011.05.021.

[21] Quiévy N, Jacquet N, Sclavons M, Deroanne C, Paquot M, Devaux J. Influence of homogenization and drying on the thermal stability of microfibrillated cellulose. Polym Degrad Stab, 95, 306 (2010) http://dx.doi.org/10.1016/j.polymdegradstab.2009.11.020.

[22] Mathur RB, Bahl OP, Mittal J, Nagpal KC. Structure of thermally stabilized PAN fibers. Carbon, 29, 1059 (1991). http://dx.doi org/10.1016/0008-6223(91)90189-P.

[23] Yu MJ, Bai YJ, Wang CG, Xu Y, Guo PZ. A new method for the evaluation of stabilization index of polyacrylonitrile fibers. Mater Lett, 61, 2292 (2007). http://dx.doi.org/10.1016/j.matlet.2006.08.071.

[24] Alcañiz-Monge J, Cazorla-Amorós D, Linares-Solano A, Oya A Sakamoto A, Hosm K. Preparation of general purpose carbon fibers from coal tar pitches with low softening point. Carbon, 35 1079 (1997). http://dx.doi.org/10.1016/S0008-6223(97)00064-X.

[25] Mora E, Blanco C, Prada V, Santamaría R. Granda M, Menéndez R. A study of pitch-based precursors for general purpose carbon fibers. Carbon, 40, 2719 (2002). http://dx.doi.org/10.1016/S00086223(02)00185-9. 